\title{
A NEW CLINICAL FORM OF HETEROCHROMIA OF THE IRIS WITH PIGMENTATION OF THE SCLERA AND PIGMENTARY GLAUCOMA*
}

\author{
BY \\ V. CAVKA \\ Beograd, Yugoslavia
}

THE significance of pigmentation of the anterior segment of the eye in the development of glaucoma, especially in the area of the trabecula of the chamber angle, has been studied by many authors.

von Hippel (1901) considered that glaucoma was due to obstruction of the chamber angle with pigment (Hanssen, 1923). Levinsohn (1908) microscopically established infiltration of the chamber angle by pigmented granules. The corneal pigment spindle (Krukenberg, 1899a, b), as well as pigmentations of the anterior surface of the iris, anterior capsule of the lens, zonular fibres, vitreous body, and chamber fluid, were all included in the analysis of the symptomatology of pigmentary glaucoma.

Among the older authors, Koeppe (1916a, b), in his clinical and microscopic findings, stressed the importance of pigmentation in the anterior sector of the eye in the development of glaucoma. In cases in which the intra-ocular pressure was not yet increased, he used the term preglaucomatous condition. Other authors who contributed to the study of this problem include Kraupa (1917), Hanssen (1923), Koby (1927), and Vogt (1930). Sugar (1940) mentioned finding pigment in the chamber angle in a case of chronic glaucoma. Sugar and Barbour (1949) described the clinical picture of pigmentary glaucoma. Later authors included Calhoun (1953), Bick (1957), Malbrán (1957), Scheie and Fleischhauer (1958), and van Beuningen (1959).

It is thought that the following cases of heterochromia of the iris represent a certain link with pigmentary glaucoma:

\section{Case Reports}

Case 1, a man aged 53 years, from Osijek, was examined in November, 1958.

Right Eye.-There was slight pigmentation on the posterior surface and in the centre of the cornea. The iris was greyish-green and there were spots of pigment scattered over the surface of the iris and tiny pigmented naevi. At the same time there was a slight ectropion of the uvea and visible spots of pigment on the anterior capsule of the lens. Other findings in the eye were normal (Fig. 1).

Fig. 1.-Case 1, aged 53 years, heterochromia of the iris with pigmentary glaucoma in both eyes.

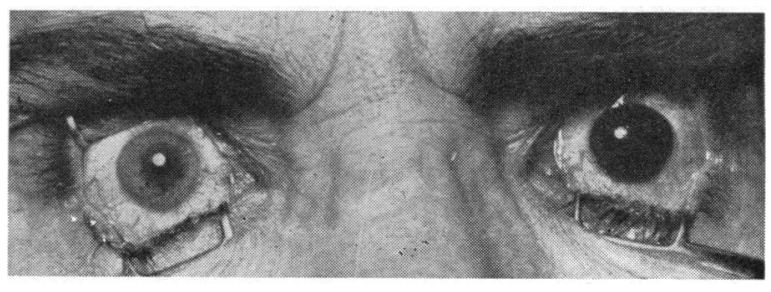

${ }^{*}$ Received for publication September 1, 1960. 
The visual acuity was $6 / 15$, and with $+1 \mathrm{D}$ sph. it was $6 / 6$.

The intra-ocular pressure was $30 \mathrm{~mm}$. $\mathrm{Hg}$., and $38 \mathrm{~mm}$. $\mathrm{Hg}$. after provocation.

Gonioscopy showed that the corneal angle was unobstructed, and the pigmentation of the trabecula was medium. Translumination showed no changes.

Left Eye.-Apart from diffuse pigmentation of the sclera in the lower portions, there was a definite Krukenberg spindle on the posterior surface of the cornea with small dots. The chamber fluid showed no cellular elements. The iris was dark brown in colour with marked pigmented layers which, in the pupillary zone for a width of 2 to $3 \mathrm{~mm}$., gave the impression of continuous pigmented granules, while in the other portions they presented as layers of pigment of the naevoid sponge-like form. The iris was consequently thicker than normal so that the normal structure was not visible at all on the surface. Biomicroscopically this marked pigmentation presented the type of intensively-developed hypertrophy not only of the pigmented granules but also of the pigment cells. There were numerous tiny pigmented dots on the anterior capsule of the lens. The papilla showed a glaucomatous excavation and a pigmented conus temporally.

The visual acuity was $6 / 30$, and with $+1.5 \mathrm{Dsph}$. it was $6 / 10$.

The field of vision was concentrically narrowed by $40^{\circ}$ to $50^{\circ}$ for red and white.

The intra-ocular pressure was $50 \mathrm{~mm}$. Hg.

Gonioscopy showed intensive pigmentation of the trabecula with pigmentation of Schwalbe's line. Translumination of the iris and ciliary body showed no changes.

All clinical and laboratory findings were normal.

Case 2, a child aged 3 years from Kragujevac, was examined in November, 1959. The eyes were seen to be of different colours (Fig. 2).

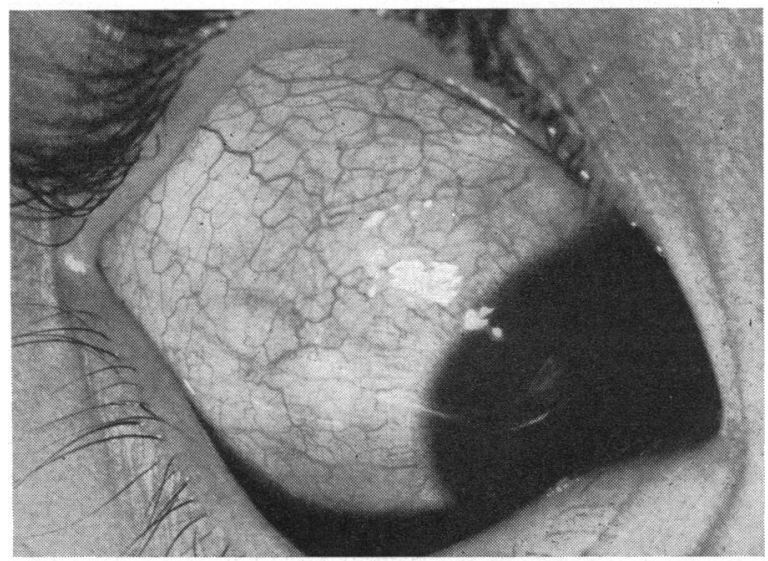

Fig. 2.-Case 2, aged 3 years, the darker right eye shows melanotic changes of the sclera with hyperpigmentation of the iris.

Right Eye.-There was pigmentation of the sclera in the temporal and upper portion, and tiny pigmented dots on the cornea from the centre of the cornea downwards in the form of a triangle with the point turned upwards. The iris was dark brown with intensive pigmentation all over the anterior surface. The pigmentation was partly granulated, forming insular foci with intensive hypertrophy of the pigment, so that the iris presented a thickened structure throughout its surface with no visible normal structure. On the anterior capsule of the lens there were numerous tiny pigmented spots. The fundus along the papillary edge showed a circumferential pigmented conus, while ophthalmoscopically the pigmented layer of the retina was overdeveloped with intensively pigmented fundus. The visual acuity was impossible to determine. 
The intra-ocular pressure was $45 \cdot 8 \mathrm{~mm}$. Hg.

Gonioscopy showed intensive pigmentation of the trabecula reaching Schwalbe's line. The chamber angle was uneven because of pigmented lumps. Translumination of the iris and ciliary body showed no changes.

Left Eye.-The cornea showed no pigmentation. There were tiny pigmented dots in the iris, in some places scattered all over the surface. The anterior capsule of the lens showed dotted pigmentations but to a much lesser extent than in the right eye. There was no pigmented conus on the fundus.

The visual acuity was impossible to determine.

The intra-ocular pressure was $35.8 \mathrm{~mm}$. Hg. As the child was very restless, it was not possible to perform a tonography.

Gonioscopy showed less marked pigmentation of the trabecula, and the iris and ciliary body showed no changes.

Iridencleisis of the right eye had already been performed; on this occasion a small section was taken for examination. Microscopically unusually intensive pigmentation of the iris tissue was established, individual cells showing intensive pigmentation (Fig. 3).

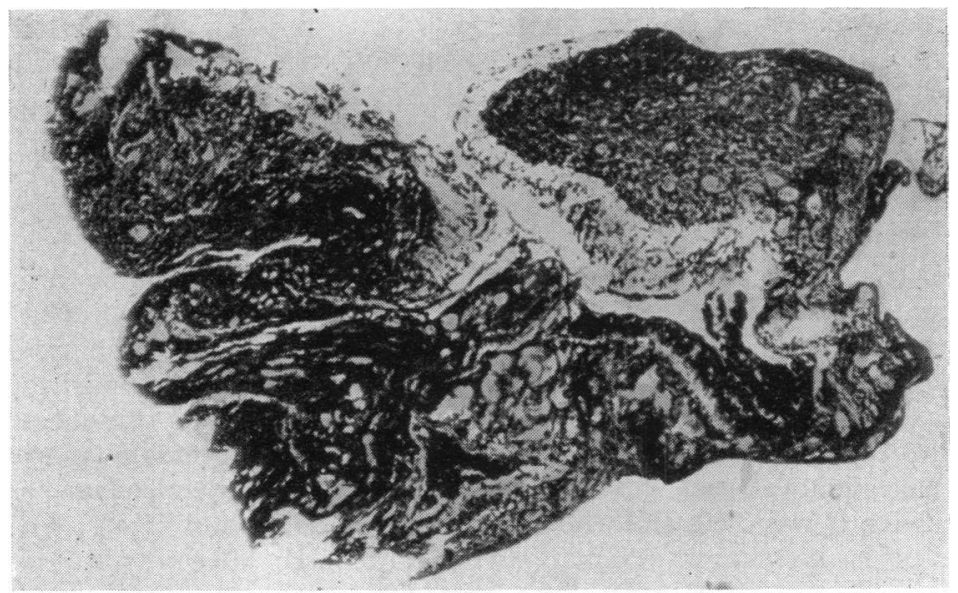

Fig. 3.-Case 2, showing diffuse and granulated pigmentation of the iris with many pigmented cells in the stroma of the iris (haemalum $\times 300$ ).

Case 3, a man aged 50 years from Gospic, was examined in November, 1959.

Right Eye.-There were melanotic changes of the sclera in the lower and temporal portion, and there was a Krukenberg corneal spindle. There were tiny dotted pigmentations on the anterior capsule of the lens. The iris showed dark pigmentation of the entire surface with slightly marked irregular pigmented granulations, and the structure as a whole was thickened. The normal structure of the iris surface had completely disappeared. There was a pigmented crescent on the temporal side of the disc.

The visual acuity was $6 / 6$.

The intra-ocular pressure was $20 \mathrm{~mm}$. $\mathrm{Hg}$ and $22 \mathrm{~mm}$. $\mathrm{Hg}$ after provocation.

Left Eye.-There was no Krukenberg spindle; the iris was light brown in colour. Other findings were normal.

The visual acuity was $6 / 6$.

The intra-ocular pressure was $20 \mathrm{~mm} . \mathrm{Hg}$ and $23 \mathrm{~mm} . \mathrm{Hg}$ after provocation.

Gonioscopy showed on the right marked dotted pigmentation of the trabecula up to Schwalbe's line. On the left side the pigmentation was poorly defined. 
Translumination of the iris and ciliary body showed nothing abnormal.

Radiography of the head and spine was normal.

Case 4, a man aged 49 years from Mitrovica, was examined in March, 1959.

Right Eye.-There was a corneal Krukenberg spindle; the iris was greyish green, with a little fine pigment on the surface of the iris, and the iris structure was normal. Other findings were normal.

The visual acuity was $6 / 6$.

The intra-ocular pressure was $18.5 \mathrm{~mm}$. $\mathrm{Hg}$ and $23 \mathrm{~mm}$. $\mathrm{Hg}$ after provocation.

Gonioscopy showed slight trabecular pigmentation.

Left Eye.-The Krukenberg spindle was more marked than in the right eye. The chamber fluid was normal. The iris showed intense pigmented hypertrophy in the form of sponge-like confluent pigmentation, and there was also hypertrophy of the pigment of the granular type so that the surface of the iris had lost its normal structure. There were numerous pigmented spots on the anterior capsule of the lens, and a glaucomatous excavation of the disc.

The visual acuity was $4 \cdot 5 / 60$ and the field of vision was concentrically narrowed.

The intra-ocular pressure was $54 \cdot 2 \mathrm{~mm}$. Hg.

Gonioscopy showed strongly marked pigmentation with granular and dotted forms.

Translumination of the iris and ciliary body was normal.

Melanin and melanogen were normal.

Radiography of the head and spine was normal.

Case 5, a child aged 7 years from Sarajevo, was examined on April 13, 1959.

Left Eye.-The lower portion of the sclera showed pigmentation in the form of spots. There was a Krukenberg's corneal spindle. The iris was darker brown than the other eye with hypertrophic pigmented changes and slight thickening. Examined under the biomicroscope this pigment hypertrophy was seen in the form of diffuse pigmented layers, and no granular structure could be discerned. On the anterior capsule of the lens dotted pigment was more marked in the left eye. On the disc nasally and temporally a pigmented crescent was seen, while the fundus was more strongly pigmented as a whole.

The visual acuity was $5 / 60$, and with $+3 \mathrm{D}$ cyl., axis $85^{\circ}$, it was $6 / 24$.

The intra-ocular pressure was $20 \mathrm{~mm}$. $\mathrm{Hg}$ and $23 \mathrm{~mm}$. $\mathrm{Hg}$ after provocation.

Gonioscopy showed strong pigmentation of the trabecula, more lightly marked in the area of Schwalbe's line.

Right Eye.-There was superficial slight dotted pigmentation on the surface of the iris. The visual acuity was $5 / 60$, and with $+2 \mathrm{D}$ sph., $+0.5 \mathrm{D}$ cyl., axis $90^{\circ}$ it was $6 / 10$.

The intra-ocular pressure was $18 \mathrm{~mm}$. $\mathrm{Hg}$ and $20 \mathrm{~mm}$. $\mathrm{Hg}$ after provocation.

Gonioscopy showed trabecular pigmentation.

Translumination of the iris and ciliary body was normal in both eyes.

Clinical and laboratory findings were normal.

Melanin and melanogen were not found in the urine.

Radiography of the head and spine was normal.

\section{Review of Findings}

The chief facts are assembled in Table I (opposite). The pigmentation of the trabecula was in all cases in keeping with the intensity of the pigmented hypertrophy of the iris, the latter being thickened to about one-fifth to one-quarter above its normal size. Only in Case 5 was the trabecular pigmentation less intense in the more pigmented eye. 
TABLE I

GENERAL CHARACTERISTICS OF FIVE CASES OF HETEROCHROMIA OF THE IRIS

\begin{tabular}{|c|c|c|c|c|c|c|c|}
\hline \multirow{2}{*}{$\begin{array}{l}\text { Case } \\
\text { No. }\end{array}$} & \multirow{2}{*}{$\begin{array}{c}\text { Age } \\
\text { (yrs) }\end{array}$} & \multicolumn{2}{|c|}{$\begin{array}{l}\text { Krukenberg } \\
\text { Spindle }\end{array}$} & \multicolumn{2}{|c|}{$\begin{array}{l}\text { Increased } \\
\text { Intra-ocular } \\
\text { Pressure }\end{array}$} & \multirow{2}{*}{$\begin{array}{l}\text { More Dotted } \\
\text { Pigmentation } \\
\text { on Anterior } \\
\text { Capsule of } \\
\text { Darker Eye }\end{array}$} & \multirow{2}{*}{$\begin{array}{l}\text { More Intensive } \\
\text { Pigmentation } \\
\text { in Chamber } \\
\text { Angle of } \\
\text { Darker Eye }\end{array}$} \\
\hline & & $\begin{array}{l}\text { Lighter } \\
\text { Eye }\end{array}$ & $\begin{array}{c}\text { Darker } \\
\text { Eye }\end{array}$ & $\begin{array}{l}\text { Lighter } \\
\text { Eye }\end{array}$ & $\begin{array}{c}\text { Darker } \\
\text { Eye }\end{array}$ & & \\
\hline 1 & 53 & + & ++ & No & Yes & + & + \\
\hline 2 & 3 & - & ++ & No & Yes & + & + \\
\hline 3 & 50 & + & ++ & No & No & + & + \\
\hline 4 & 49 & + & ++ & No & Yes & + & + \\
\hline 5 & 7 & - & ++ & No & No & + & + \\
\hline
\end{tabular}

Furthermore, translumination of the iris and ciliary body in both eyes showed normal findings and in no sector was it possible to establish even incipient atrophy of the tissue, by this method, with a diascleral lamp, or biomicroscopically. As already mentioned, in all these five cases with pigmentary glaucoma, there were no symptoms of heterochromia with cyclitis (Fuchs) nor any symptomatic heterochromia. All tests to elicit an altered sympathetic apparatus, either locally in the eye or in the cervical portion of the spine, remained negative. Considering that the history recorded heterochromia of the iris from birth, we consider this anomaly to be congenital and different from ordinary heterochromia of the iris in which there are no pathological symptoms of the eyes as were established in our cases.

These five cases of a hypertrophic-pigmented form of pigmentary glaucoma with heterochromia of the iris present a new clinical picture of hyperpigmentary glaucoma, which is most probably due aetiologically to congenital hypertrophy of the pigmented layer of the iris leading to a considerable production of pigment on the anterior surface of the iris and in the chamber angle. It is possible that hypertrophic changes had occurred in the pigment cells close to the ciliary processes.

It is especially significant that in these five cases, apart from pigmented hypertrophy on the darker eye together with intensive pigmented accumulations in the area of the whole trabecula up to the line of Schwalbe, the intraocular pressure was markedly higher in the darker and more pigmented eye. Only in Cases 3 and 5 was it not possible to establish an increased intra-ocular pressure even by provocation. 
The symptoms are classified in Table II.

TABLE II

CLASSIFICATION OF SYMPTOMS IN HETEROCHROMIC EYES

\begin{tabular}{|c|c|c|}
\hline No. & Lighter Eye & Darker Eye \\
\hline $\begin{array}{l}1 \\
2\end{array}$ & $\begin{array}{l}\text { No melanotic changes on the sclera } \\
\text { Krukenberg spindle of the cornea non- }\end{array}$ & $\begin{array}{l}\text { Melanotic changes on the sclera } \\
\text { Krukenberg spindle of the cornea more }\end{array}$ \\
\hline 3 & $\begin{array}{l}\text { existent or slightly marked } \\
\text { Only dotted pigmentation on the iris }\end{array}$ & $\begin{array}{l}\text { marked } \\
\text { Intensive hypertrophic granular and } \\
\text { naevoid pigmentation of the iris }\end{array}$ \\
\hline 4 & $\begin{array}{l}\text { Slight or medium pigmentation of the } \\
\text { trabecula }\end{array}$ & Intensive pigmentation of the trabecula \\
\hline 5 & Pigmented crescent of the disc non-existent & $\begin{array}{l}\text { Very marked pigmented crescent of the } \\
\text { disc }\end{array}$ \\
\hline 6 & $\begin{array}{l}\text { Intra-ocular pressure normal or only } \\
\text { slightly increased }\end{array}$ & $\begin{array}{l}\text { Intra-ocular pressure more or less } \\
\text { intensively increased }\end{array}$ \\
\hline 7 & \multicolumn{2}{|c|}{ Translumination of both eyes normal } \\
\hline
\end{tabular}

\section{Discussion}

According to these symptoms we managed to establish a new clinical form of heterochromia of the iris linked with melanotic changes (i.e. intensive pigmentation in the sclera, cornea, iris, and chamber angle, and in the area of the optic disc and retina, always more marked in the darker eye).

The pigmentary glaucoma established in three cases $(1,2$, and 4$)$ does not exclude the possibility that glaucoma may occur in due time in the other two patients as well, especially considering the intensive trabecular pigmentation seen in the darker eye in both of them. In Case 2, the microscopic findings in the excised part of the iris revealed, not only intensive diffusely scattered pigmented conglomerations and granules, but also large numbers of pigmented melanophoric cells. Accordingly the microscopic slide of the iris showed, not only pigmented cells, but also scattered, free, extracellular pigment. However, it was not possible to discover pathological mitoses or any other malignant changes in the cells.

The changes found in these cases, considered with the case history, indicate a congenital affliction of the eye, in which the pigment was most probably transported by the chamber fluid from the iris to the chamber angle, through the obstruction of the latter by pigment with the consequent occurrence of glaucoma. There was also slight pigmentation in the iris and chamber angle in the lighter eye, which might well be considered as a pathological finding. The establishment of glaucomatous hypertension in the lighter eye in two cases ( 1 and 2) confirms our opinion that there was pathological pigment in the chamber angle in the lighter eye also. The proliferation of pigment with obstruction of the chamber angle was most probably the only cause of the occurrence of the congenital pigmentary glaucoma in either eye. 
Summary

In five patients whose ages ranged from 3 to 53 years, it was possible to establish a new ocular syndrome; melanotic changes in the sclera and retina, hyperpigmentation of the iris and chamber angle with heterochromia of the iris; and the clinical picture of pigmentary glaucoma. All the pigmentation in the eye is assumed to have occurred congenitally, and they may be described as cases of congenital pigmentary glaucoma.

\section{REFERENCES}

Beuningen, E. G. A. Van (1959). Klin. Mbl. Augenheilk., 135, 796.

BiCK, M. W. (1957). A.M.A. Arch. Ophthal., 58, 483.

Calhoun, F. P., (1953). Amer. J. Ophthal., 36, 1398.

HANSSEN, R. (1923). Klin. Mbl. Augenheilk., 71, 399.

HIPPEL, E. voN (1901). v. Graefes Arch. Ophthal., 52, 498.

KoBY, F. E. (1927). Bull. Soc. Ophtal. Paris, 124.

KOEPPE, L. (1916a). Ber. 40 Versammlung ophthal. Ges. Heidelberg, p. 478. (1916b). v. Graefes Arch. Ophthal., 91, 363.

KraUPA, E. (1917). Arch. Augenheilk., 82, 67.

Krukenberg, F. (1899a, b). Klin. Mbl. Augenheilk., 37, 254, 478.

LeVInsohn, G. (1908). Arch. Augenheilk., 62, 131.

Malbrán, J. (1957). Mod. Probl. Ophthal., 1, 132.

ScheIe, H. G., and FleischHauer, H. W. (1958). A.M.A. Arch. Ophthal., 59, 216.

Sugar, H. S. (1940). Amer. J. Ophthal., 23, 853. and BARBOUR, T. A. (1949). lbid., 32, 90

VoGt, A. (1930). "Lehrbuch und Atlas der Spaltlampenmikroskopie des lebenden Auges". Springer, Berlin. 